\title{
Proteomic analysis of oxidative stress-induced neuronal cell death by using two-dimensional fluorescence difference gel electrophoresis
}

\author{
EUN YOUNG KIM ${ }^{1}$, TAE-SUNG YOON ${ }^{1}$, YOUNG JAE BAHN ${ }^{2}$, DAE GWIN JEONG ${ }^{1}$, MI RIM PARK ${ }^{2}$, \\ SANG J. CHUNG ${ }^{3}$, SUNG GOO PARK ${ }^{1}$, BYOUNG CHUL PARK ${ }^{1}$, SANG CHUL LEE ${ }^{1}$, \\ SEONG EON RYU ${ }^{2,4}$ and KWANG-HEE BAE ${ }^{1}$ \\ ${ }^{1}$ Medical Proteomics Research Center, KRIBB, Daejeon; ${ }^{2}$ Systemic Proteomics Research Center, KRIBB, Daejeon; \\ ${ }^{3}$ BioNanotechnology Research Center, KRIBB, Daejeon; ${ }^{4}$ Department of Bio Engineering, \\ College of Engineering, Hanyang University, Seoul, Republic of Korea
}

Received April 14, 2010; Accepted June 12, 2010

DOI: 10.3892/ijmm_00000531

\begin{abstract}
Oxidative stress has been implicated in a number of neurological disorders, including cerebral ischemia and neurodegenerative diseases. Comprehensive proteomic studies were carried out using an immortalized mouse hippocampal cell line, HT22, exhibiting oxidative stress-mediated cell death upon glutamate treatment. Two-dimensional fluorescence difference gel electrophoresis (2D DIGE) of subcellular organelle fractions revealed that significant numbers of proteins showed quantitative changes during HT22 cell death, among which a total of 51 proteins were identified by mass spectrometry. The identified proteins indicate that HT22 cell death occurs through perturbations in mitochondrial function, changes in translational elongation machinery, and translocation of proteins across subcellular organelles. This list of proteins may shed light on oxidative stress-mediated neuronal cell death.
\end{abstract}

\section{Introduction}

Oxidative stress of neuronal cells is considered an important factor in the onset or progression of several neurodegenerative diseases, including Alzheimer's and Parkinson's disease, and ischemic reperfusion injury (1-3). Reactive oxygen species (ROS), which are generated as by-products of many metabolic

Correspondence to: Dr Kwang-Hee Bae, Medical Proteomics Research Center, KRIBB, 50 Eon-Dong, Yusung-Gu, Daejeon 305806, Republic of Korea

E-mail:khbae@kribb.re.kr

Dr Seong Eon Ryu, Department of Bio Engineering, College of Engineering, 17 Haengdang-dong, Seongdong-gu, Hanyang University, Seoul 133-791, Republic of Korea

E-mail: ryuse@hanyang.ac.kr

Key words: two-dimensional fluorescence difference gel electrophoresis, HT22, oxidative stress, proteomics, reactive oxygen species processes, including monoamine metabolism, mitochondrial electron transport chain and arachidonic acid oxidation, are the principal mediators of neuronal cell death. The damage caused to various macromolecules by chemical reactions with ROS can initiate cellular apoptosis or lead to cell death by necrosis $(4,5)$. However, neuronal cell death signaling is still not fully understood, and the series of events may differ depending upon the nature and concentration of apoptotic stimuli as well on as the particular neuronal population or cell types.

Glutamate induces cell death through two distinct pathways, receptor-initiated excitotoxicity and non-receptormediated oxidative glutamate toxicity (6). The HT22 mouse hippocampal cell line that phenotypically resembles neuronal precursor cells has been used in model studies of glutamateinduced oxidative toxicity (6-8). Since this cell line lacks functional ionotropic glutamate receptors, the effect of glutamate on these cells is not due to receptor-initiated excitotoxicity (9), but is related to the glutamate/cystine antiporter, which is required for the delivery of cystine into neuronal cells. Inhibition of cystine uptake by glutamate leads to depletion of cellular glutiathone $(\mathrm{GSH})$, activation of neuronal 12-lipoxygenase (12-LOX), accumulation of ROS, and elevation of intracellular $\mathrm{Ca}^{2+}$. Increased $\mathrm{ROS}$ production and high $\mathrm{Ca}^{2+}$ levels are important requirements for the initiation of the apoptotic pathway. It is noteworthy that a similar nonreceptor-mediated glutamate oxidative toxicity has been reported in immature cortical neurons, implying that the mechanisms responsible for glutamate toxicity in HT22 cells may apply to some in vivo cases (10). Therefore, the oxidative pathway of glutamate toxicity serves as a model to study the response of neuronal cells to oxidative stress $(7,8)$.

Although many research groups have studied glutamate toxicity in HT22 cells, global systematic studies on its detailed mechanism have not been carried out. In this study, we carried out extensive proteomic studies on glutamatetreated HT22 cells to identify the candidate key proteins that mediate neuronal injury. By using two-dimensional fluorescence gel electrophoresis (2D DIGE) analysis after 
prefractionation of HT22 cells treated with glutamate, we identified a total of 51 spots that were up- or down-regulated by oxidative stress, most of which are involved in protein folding, anti-oxidant functions, translation elongation, cytoskeletal remodeling, and the general apoptosis pathway. The information obtained from our proteomic studies could help identify which proteins are involved in glutamate-induced oxidative stress in neuronal cells, thereby increasing our understanding of the neuronal cell death pathway.

\section{Materials and methods}

Antibodies and reagents. Electrophoresis reagents including acrylamide solution, Immobiline dry strip, IPG buffer and IPG cover mineral oil were purchased from GE Healthcare. The anti-histone, Sp1, and VDAC monoclonal antibody were purchased from Santa Cruz Biotechnology Inc. All other chemicals and enzymes including fluorescent dyes were from Sigma or GE Healthcare.

Sample preparation and 2D DIGE. The mouse HT22 hippocampal cell line was maintained in Dulbecco's modified Eagle's medium (Gibco BRL, Gaithersburg, MD) with 10\% fetal bovine serum (Atlanta Biologicals, Atlanta, GA). Cell viability was assessed by measuring their ability to metabolize 3-(4,5dimethyldiazol-2-yl)-2,5-diphenyltetrazolium bromide (MTT), and the assay was carried out according to the manufacturer's recommendations.

The cytosol, nucleus, and mitochondria fractions were prepared by differential centrifugation (11). The fractionated samples were solubilized in a lysis buffer (30 mM Tris $\mathrm{pH} 8.5$, $7 \mathrm{M}$ urea, $2 \mathrm{M}$ thiourea, and 4\% 3-[(3-cholamidopropyl)dimethylammonio] propanesulfonate [CHAPS]). CyDyes (Cy2, 3, and 5 from GE Healthcare) were then added to each protein lysate and incubated on ice in the dark for $30 \mathrm{~min}$. Protein samples to be separated on the same gel were pooled and 3 volumes of acetone were added. After centrifugation, the precipitate was re-hydrated using a rehydration buffer $(7 \mathrm{M}$ urea, $2 \mathrm{M}$ thiourea, 4\% CHAPS, 2\% ampholyte and $20 \mathrm{mM}$ DTT), and isoelectric focusing was carried out using a Multiphor II (GE Healthcare) apparatus. After focusing, each strip was equilibrated twice for $15 \mathrm{~min}$ in $2 \times 2.5 \mathrm{ml}$ equilibrium buffer. The equilibrium buffer contains $50 \mathrm{mM}$ Tris $\mathrm{pH} 8.8,6 \mathrm{M}$ urea, and 30\% glycerol. During the second equilibrium step, $260 \mathrm{mM}$ iodoacetamide was added to the equilibrium buffer. The IPG strips were then loaded and separated on a $12 \%$ acrylamide SDS-PAGE gel using a DALT12 (GE Healthcare) apparatus. Images were acquired with a Typhoon 9410 scanner (GE Healthcare) using 520BP40 (Cy2), 580BP30 (Cy3), and 670BP30 (Cy5) emission filters. The resolution was set to $100 \mu \mathrm{m}$. Images were analyzed using the DeCyder Differential Analysis Software v5.0 (GE Healthcare) in both the DIA and BVA module. Only spots with 2 -fold changes in volume after normalization in at least three separate experiments $(\mathrm{P}<0.05)$ were defined as altered.

Protein identification with mass spectrometry. The separated proteins in SDS-PAGE gels were visualized by silver staining. The stained gel images were compared with the original DeCyder analysis experiments and matched. The spots of a.
b.
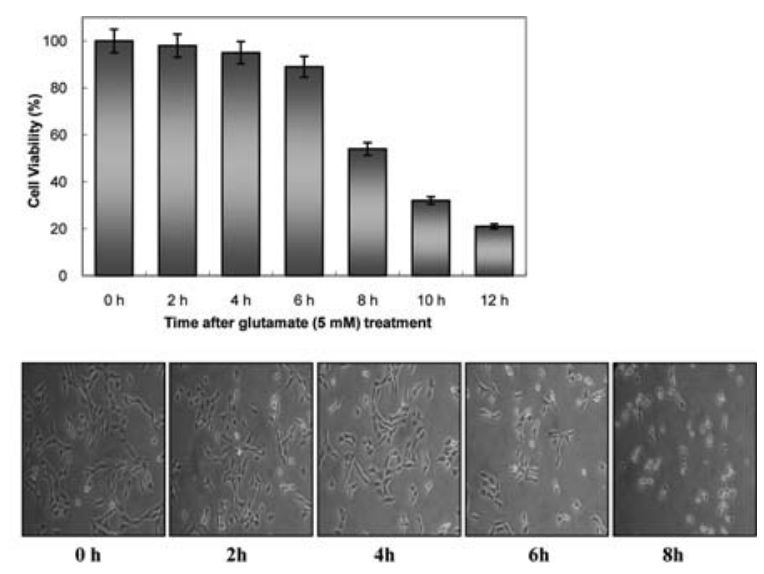

c.

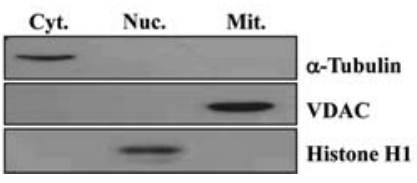

Figure 1. Effect of glutamate-induced oxidative toxicity on HT22 cell viability. (a) Effect of glutamate on HT22 cell viability. HT22 cells were seeded into 96-well plates at 5,000 cells per well and grown for $24 \mathrm{~h}$. Cells were then treated with $5 \mathrm{mM}$ glutamate. At each time point, cell viability was measured using an MTT assay. (b) Light microscopic morphology of glutamate-treated HT22 cells. Morphology of HT22 cells treated with $5 \mathrm{mM}$ glutamate was changed. (c) Confirmation of HT22 cell fractionation quality using fractionspecific antibodies.

interest were either manually excised or automatically detected and excised using the Xcise ${ }^{\mathrm{TM}}$ apparatus (Shimadzu Biotech, Japan). Gel pieces were washed twice with $150 \mu 1$ of $100 \mathrm{mM}$ ammonium bicarbonate $(\mathrm{pH} \mathrm{8.2)}$ and $70 \% \mathrm{v} / \mathrm{v}$ acetylnitrile $(\mathrm{ACN})$, and dried at $37^{\circ} \mathrm{C}$ for $20 \mathrm{~min}$. Trypsin in $50 \mathrm{mM}$ ammonium bicarbonate $(20 \mu \mathrm{g} / \mu \mathrm{l})$ was added to each gel piece and incubated at $37^{\circ} \mathrm{C}$ for $2 \mathrm{~h}$. Peptides were then extracted using a mixture containing $20 \mu \mathrm{l}$ of $0.1 \% \mathrm{v} / \mathrm{v}$ trifluoroacetic acid (TFA) and 70\% ACN. The peptide solution was either manually or automatically desalted and concentrated using ZipTips $^{\mathrm{TM}}$ (Millipore, Bedford, MA) $(8,12)$, and spotted onto an Axima Maldi target plate. The peptide mass spectra of tryptic peptides were generated by using an Axima CFR+ matrix-assisted laser desorption/ionization time-of-flight mass spectrometer (MALDI-TOF-MS; Shimadzu Biotech, Japan). The peptide masses were matched with the theoretical peptide masses obtained from the mouse database of the NCBInr using Mascot with the automated Mascot Daemon v.2.0 (Matrix Sciences, London, UK).

Western blot analysis. Fractionated samples were resuspended in an SDS sample buffer $(62.5 \mathrm{mM}$ Tris- $\mathrm{HCl} \mathrm{pH} 6.8,2.3 \%$ SDS, $10 \%$ glycerol, $5 \%$ 2-mercaptoethanol and $0.005 \%$ bromophenol blue). Proteins (10-50 $\mu \mathrm{g}$ ) were separated by SDS-PAGE in $12 \%$ gels and detected immunologically after electrotransfer onto nitrocellulose membranes. Membranes were blocked in phosphate-buffered saline (PBS) containing 5\% powdered skim milk and $0.05 \%$ Tween-20 for $2 \mathrm{~h}$ at room temperature. Membranes were then incubated overnight with goat anti-mouse primary antibody in blocking solution and 


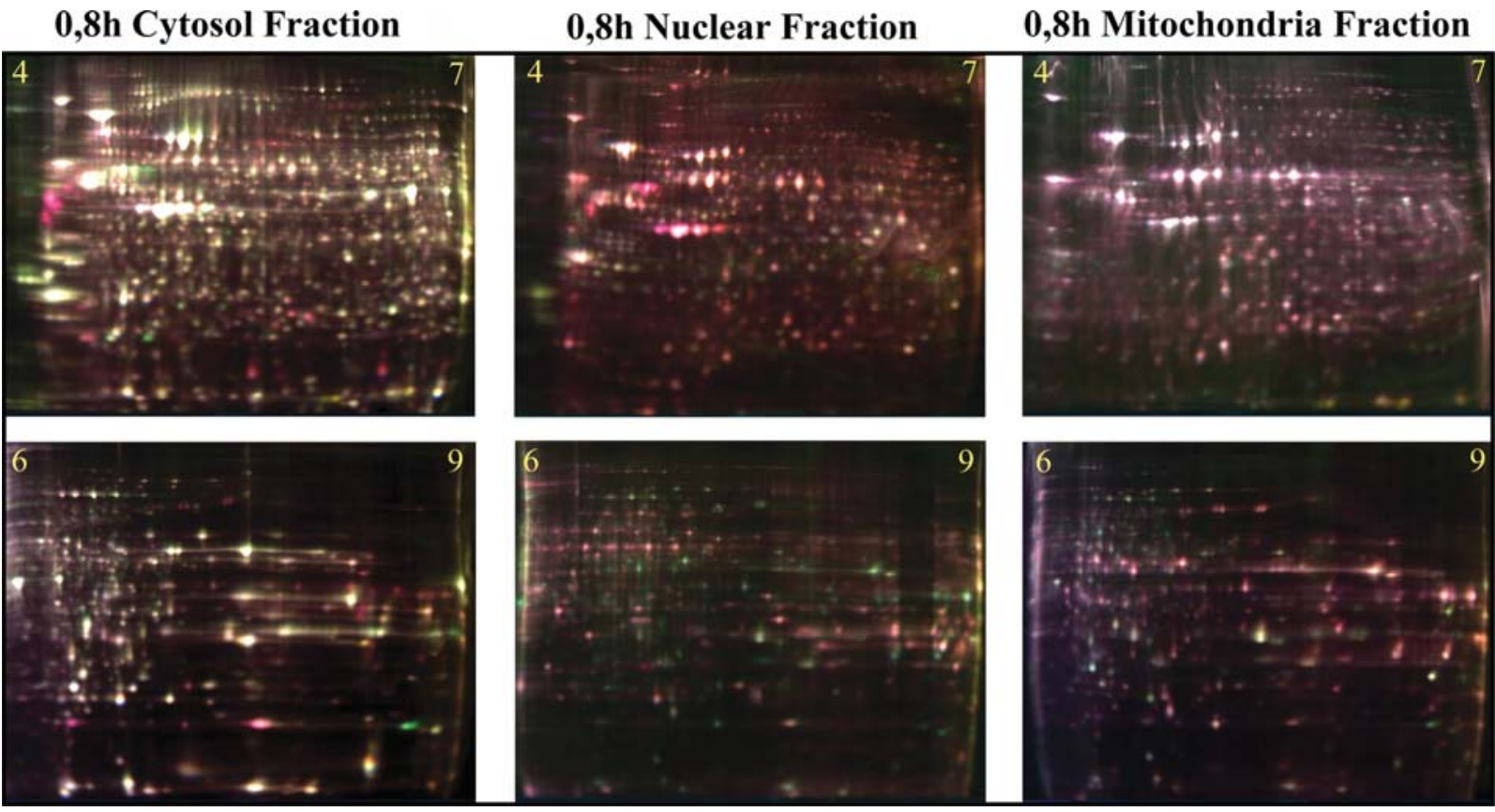

Figure 2. Representative 2D DIGE images of each subcellular fraction. Samples were prepared as described in Materials and methods. Pooled standard, $0 \mathrm{~h}$ control, and 8 h glutamate-treated samples were labeled with Cy2, Cy3, and Cy5 (or Cy2, Cy5, and Cy3), respectively. They were then loaded on a gel and scanned with CyDye-specific wavelength using a Typhoon 9410 scanner.

then with horseradish peroxidase-conjugated anti-goat $(1: 2,000)$ IgG for $1 \mathrm{~h}$. Blots were visualized using the Amersham ECL system.

\section{Results and Discussion}

Identification of altered proteins. As an initial step, cell viability after glutamate treatment was assayed using an MTT-based assay. As shown in Fig. 1A, there was no significant change in HT22 cell viability until $6 \mathrm{~h}$ after the addition of glutamate. Cell viability gradually decreased between 6 and 8 h. About 70\% of HT22 cells died at 8 h. In addition, HT22 cells treated with $5 \mathrm{mM}$ glutamate continuously changed into shrunken, rounded cells (Fig. 1B). On the base of these data, we decided to analyze the proteome changes in HT22 cells between $0-8 \mathrm{~h}$ after treatment with $5 \mathrm{mM}$ glutamate.

We fractionated HT22 cells into three portions (cytosol, nucleus, and mitochondria) by using a differential centrifugation method (11). We tested the fractionation quality of every sample used in proteomic analyses by using antibodies against suborganelle-specific marker proteins (Fig. 1C). Protein spots that exhibited changes $>2$-fold in magnitude in three or more replicated gels were selected for peptide fingerprinting. The analysis of the fractions by gel electrophoresis after $8 \mathrm{~h}$ of glutamate treatment showed 49,21 , and 36 reproducible protein changes in the cytosol, mitochondria, and nucleus fractions, respectively (data not shown). Among these, 33, 18, and 21 proteins were identified by peptide fingerprinting using MALDI-TOF mass spectrometry. Proteins known to be located in the cytosol, such as actin, tubulin and vimentin, were identified in the nucleus fraction as differentially expressed proteins (data not shown). Thus, we focused our analysis on data from the cytosol and mitochondria fractions (Table I; Fig. 2).
Cellular defence against oxidative stress. Heat shock protein 70 (HSP70) was up-regulated in the cytosol fraction. This protein is a molecular chaperone that protects other proteins during cellular stress $(13,14)$. Previously, it was reported that glutamate-induced HT22 cell death was attenuated in cells overexpressing HSP70 (15). Under normal conditions, HSP70 functions as an ATP-dependent chaperone by assisting the folding of newly synthesized proteins and polypeptides, the assembly of multi-protein complexes, and the transport of proteins across cellular membranes $(16,17)$. When HSP70 is up-regulated by cellular stress, it interacts with several components of apoptotic machinery including Apaf-1 and apoptosis-inducing factor (AIF), indicating that HSP70 may affect the apoptosis signaling pathway in addition to directly protecting protein unfolding $(16,17)$.

Antioxidant proteins, such as several peroxiredoxins and superoxide dismutase 2 , were differentially regulated in the cytosol or mitochondria fractions. Previously, it was reported that peroxiredoxin 1 and 5 have been shown to ameliorate ROS-induced cytotoxicity (18). These results clearly showed that the defense system involving antioxidant enzymes against oxidative stress is activated by glutamate-induced stress. In addition to antioxidant proteins, $\mathrm{NADP}^{+}$-specific isocitrate dehydrogenase was up-regulated in the cytosol. Cytosolic $\mathrm{NADP}^{+}$-specific isocitrate dehydrogenase appears to modulate the status of oxidative damaged cells (19). This protein was highly overexpressed in the cytosolic fraction after oxidative stress, implying the involvement of this enzyme in glutamateinduced HT22 cell death.

Cytoskeletal remodelling. Vimentin, actin $\gamma$, annexin A3, and tubulin $\alpha$ which are involved in cytoskeletal remodeling, were also identified. In particular, vimentin and tubulin were identified at several different positions. Vimentin was reported 
Table I. The identified proteins during glutamate-induced HT22 cell death.

\begin{tabular}{|c|c|c|c|c|c|c|}
\hline Spot no. & Accession no. & Protein name & Function & Moscot score & Coverage (\%) & Alteration \\
\hline $\mathrm{C}-1$ & gil29748016 & Heat shock $70 \mathrm{kD}$ protein & Molecular chaperone & 190 & 41 & $2.01 \uparrow$ \\
\hline $\mathrm{C}-3$ & gil23958822 & Glucose related protein & Molecular chaperone & 182 & 39 & $3.30 \uparrow$ \\
\hline $\mathrm{C}-4$ & gil47847514 & mFLJ00343 protein & Unknown & 74 & 9 & $\begin{array}{l}3.60 \uparrow / 3.41 \uparrow / \\
2.85 \uparrow / 2.54 \uparrow\end{array}$ \\
\hline $\mathrm{C}-5$ & gil38511951 & $\begin{array}{l}\text { Eukaryotic translation } \\
\text { elongation factor } 2\end{array}$ & Translation & 101 & 20 & $\begin{array}{c}2.62 \uparrow / 2.87 \uparrow / \\
3.78 \uparrow\end{array}$ \\
\hline C-6 & gil9845253 & $\begin{array}{l}\text { Heterogeneous nuclear } \\
\text { ribonucleoprotein } \mathrm{H} 2\end{array}$ & Translation & 134 & 42 & $2.01 \uparrow$ \\
\hline $\mathrm{C}-18$ & gil55777182 & Cofilin 1, non-muscle & Cytoskeleton & 64 & 46 & $4.23 \uparrow$ \\
\hline C-19 & gil56270600 & Nme2 protein & Metabolism & 82 & 67 & $2.23 \uparrow$ \\
\hline $\mathrm{C}-20$ & gil30519911 & Transgelin-2 & Cytoskeleton & 116 & 46 & $3.42 \uparrow$ \\
\hline $\mathrm{C}-25$ & gil51980699 & Peroxiredoxin-2 & Redox protein & 72 & 24 & $2.78 \uparrow$ \\
\hline $\mathrm{C}-28$ & gil2078001 & Vimentin & Cytoskeleton & 118 & 31 & $3.10 \uparrow$ \\
\hline C-31 & gil5902663 & Elongation factor $1 \beta$ homolog & Translation & 79 & 44 & $2.24 \downarrow$ \\
\hline $\mathrm{C}-33$ & gil2078001 & Vimentin & Cytoskeleton & 104 & 55 & $3.95 \uparrow$ \\
\hline $\mathrm{C}-34$ & gil2078001 & Vimentin & Cytoskeleton & 218 & 61 & $10.50 \uparrow$ \\
\hline $\mathrm{C}-35$ & gil2078001 & Vimentin & Cytoskeleton & 149 & 55 & $8.60 \uparrow$ \\
\hline $\mathrm{C}-36$ & gil2078001 & Vimentin & Cytoskeleton & 218 & 61 & $7.50 \uparrow$ \\
\hline $\mathrm{C}-37$ & gil49868 & Putative $\beta$-actin (aa 27-375) & Cytoskeleton & 104 & 26 & $3.28 \uparrow$ \\
\hline C-41 & gil53733821 & Tubulin $\alpha 6$ & Cytoskeleton & 79 & 38 & $2.53 \downarrow$ \\
\hline $\mathrm{C}-45$ & gil7305485 & SH3-domain GRB2-like 1 & Unknown & 92 & 35 & $2.26 \downarrow$ \\
\hline C-46 & gil55391513 & Calponin 3 , acidic & Cytoskeleton & 80 & 35 & $4.70 \downarrow$ \\
\hline C- 48 & gil18203574 & $\begin{array}{l}\text { Ubiquitin carboxyl-terminal } \\
\text { hydrolase isozyme L5 }\end{array}$ & Signal transduction & 155 & 47 & $2.39 \uparrow$ \\
\hline C-49 & gil10442752 & $\begin{array}{l}\text { Eukaryotic translation } \\
\text { elongation factor } 1 \delta\end{array}$ & Translation & 114 & 40 & $3.32 \uparrow$ \\
\hline $\mathrm{C}-50$ & gil30267702 & Peroxiredoxin 6 & Redox protein & 148 & 58 & $2.16 \downarrow$ \\
\hline C-51 & gil10442752 & $\begin{array}{l}\text { Eukaryotic translation } \\
\text { elongation factor } 1 \delta\end{array}$ & Translation & 114 & 40 & $2.77 \uparrow$ \\
\hline C-68 & gil6137391 & $\begin{array}{l}\text { Chain B, crystal structure } \\
\text { of Mgsta 4-4 }\end{array}$ & Metabolism & 72 & 38 & $3.03 \uparrow$ \\
\hline C-71 & gil17390379 & Superoxide dismutase 2 & Redox protein & 90 & 42 & $2.00 \uparrow$ \\
\hline $\mathrm{C}-72$ & gil34328230 & Adenylate kinase 2 & Signal transduction & 80 & 36 & $2.34 \uparrow$ \\
\hline $\mathrm{C}-74$ & gil56103807 & Peroxiredoxin 1 & Redox protein & 180 & 44 & $3.45 \uparrow$ \\
\hline $\mathrm{C}-75$ & gil56103807 & Peroxiredoxin 1 & Redox protein & 177 & 44 & $6.46 \downarrow$ \\
\hline C-76 & gil51772149 & $\begin{array}{l}\text { Similar to glyceraldehyde } 3 \\
\text { phosphate dehydrogenase }\end{array}$ & Metabolism & 163 & 56 & $2.69 \downarrow$ \\
\hline $\mathrm{C}-78$ & gil37748684 & $\begin{array}{l}\text { Isocitrate dehydrogenase } 2 \\
\left(\mathrm{NADP}^{+}\right)\end{array}$ & Metabolism & 150 & 44 & $4.95 \uparrow$ \\
\hline C- 80 & gil6753304 & $\begin{array}{l}\text { Serine protease inhibitor, } \\
\text { clade } \mathrm{H} \text {, member } 1\end{array}$ & Unknown & 79 & 29 & $2.29 \uparrow$ \\
\hline C-82 & gil30802174 & $\begin{array}{l}\text { Serine hydroxymethyl } \\
\text { transferase } 2 \text { (mitochondrial) }\end{array}$ & Metabolism & 198 & 43 & $2.63 \uparrow$ \\
\hline C-84 & gil7548322 & Aldolase A & Metabolism & 105 & 29 & $2.78 \uparrow$ \\
\hline M-3 & gil31542559 & $\begin{array}{l}\text { Dihydrolipoamide } \\
\text { S-acetyltransferase }\end{array}$ & Metabolism & 165 & 35 & $2.11 \uparrow$ \\
\hline M-15 & gil26353794 & Unnamed protein & Unknown & 88 & 24 & $2.74 \uparrow$ \\
\hline M-23 & gil6680690 & Peroxiredoxin 3 & Redox protein & 48 & 18 & $2.64 \uparrow$ \\
\hline M-30 & gil31981925 & Tyrosine 3-monooxygenase & Metabolism & 113 & 56 & $2.02 \downarrow$ \\
\hline M-32 & gil51593617 & $\begin{array}{l}\text { Unknown (protein for } \\
\text { IMAGE:5371853) }\end{array}$ & Unknown & 87 & 36 & $2.99 \uparrow$ \\
\hline M-36 & gil13162318 & Calcium binding protein $\mathrm{P} 22$ & Signal transduction & 123 & 76 & $2.25 \uparrow$ \\
\hline M-42 & gil6680027 & Glutamate dehydrogenase 1 & Metabolism & 262 & 54 & $2.03 \uparrow$ \\
\hline M-43 & gil1826680 & 3-oxoacid CoA transferase 1 & Metabolism & 131 & 36 & $2.11 \uparrow$ \\
\hline M-45 & gil27370092 & Tu translation elongation factor & Translation & 202 & 51 & $2.00 \uparrow$ \\
\hline M-46 & gil9789985 & Isovaleryl CoA dehydrogenase & Metabolism & 96 & 25 & $2.14 \uparrow$ \\
\hline
\end{tabular}


Table I. Continued.

\begin{tabular}{|c|c|c|c|c|c|c|}
\hline Spot no. & Accession no. & Protein name & Function & Moscot score & Coverage $(\%)$ & Alteration \\
\hline M-47 & gil31982520 & $\begin{array}{l}\text { Acetyl CoA dehydrogenase, } \\
\text { long chain }\end{array}$ & Metabolism & 106 & 33 & $2.08 \uparrow$ \\
\hline M-49 & gil31981830 & $\begin{array}{l}\text { Cytochrome c oxidase, } \\
\text { subunit VIIa } 2\end{array}$ & Metabolism & 63 & 81 & $2.05 \downarrow$ \\
\hline M-66 & gil6678952 & $\begin{array}{l}\text { Methylenetetrahydrofolate } \\
\text { dehydrogenase } 1\end{array}$ & Metabolism & 113 & 38 & $2.03 \uparrow$ \\
\hline M-70 & gil30802174 & $\begin{array}{l}\text { Serine hydroxymethyl } \\
\text { transferase } 2\end{array}$ & Metabolism & 232 & 35 & $2.13 \uparrow$ \\
\hline M-71 & gil6680748 & $\begin{array}{l}\text { ATP synthase, } \mathrm{H}^{+} \\
\text {transporting, a subunit }\end{array}$ & Metabolism & 313 & 51 & $2.18 \uparrow$ \\
\hline M-77 & gil1200100 & Malate dehydrogenase & Metabolism & 208 & 63 & $2.11 \uparrow$ \\
\hline M-84 & gil33859554 & Fumarate hydratase 1 & Metabolism & 85 & 22 & $2.02 \uparrow$ \\
\hline M-92 & gil18079339 & Aconitase 2, mitochondrial & Metabolism & 113 & 20 & $2.00 \uparrow$ \\
\hline
\end{tabular}

a.
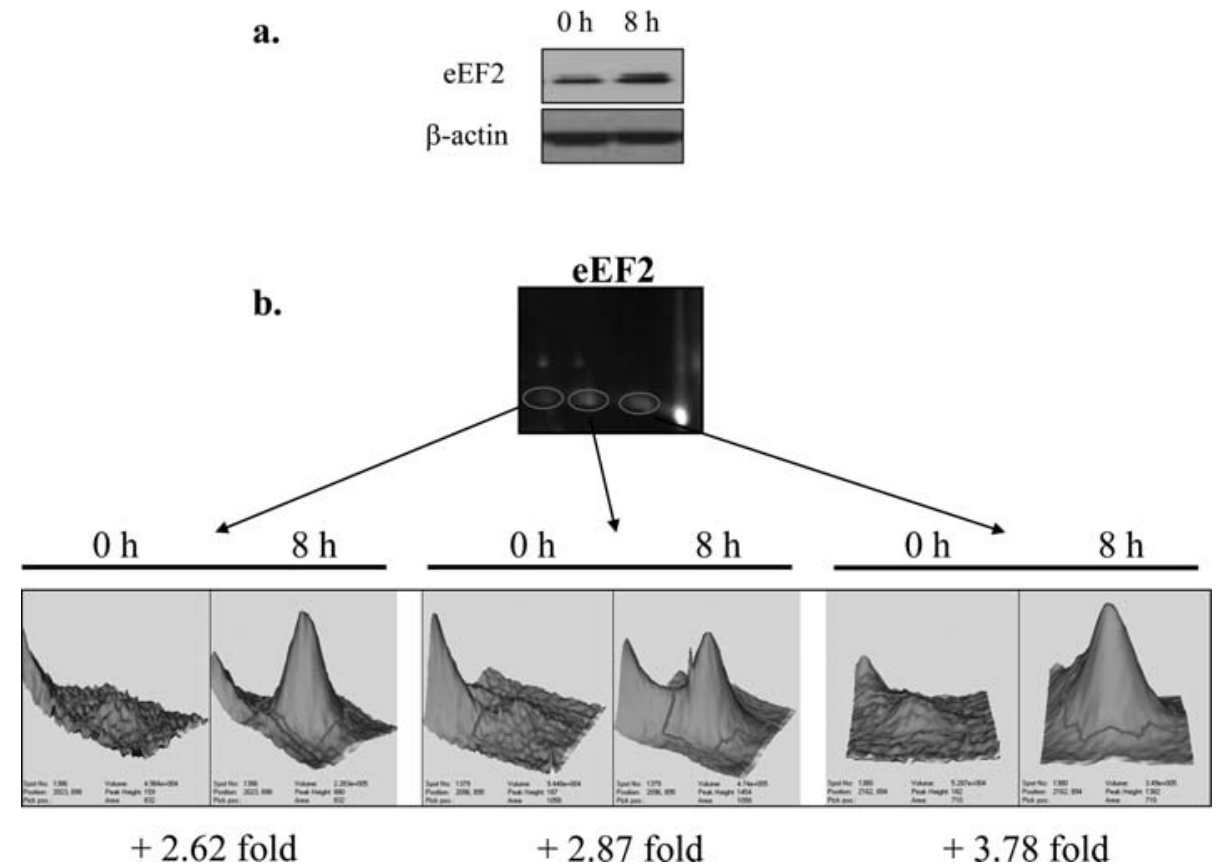

Figure 3. The quantification of eEF2 using Western blotting and DeCyder software. (a) Western blot validation of 2D DIGE results. eEF2 was selected for further validation by using Western blotting of cytosolic fraction. Western blot analysis confirmed an increase in the expression of eEF2 in glutamate-induced oxidative toxicity of HT22 cells. (b) Comparison analyses of eEF2 spot intensities by DeCyder-DIA. The post-translational modification levels of three eEF2s in response to oxidative stress are shown.

to be rapidly proteolyzed by multiple caspases into similarsized fragments during apoptosis induced by many stimuli (20). The caspase cleavage of vimentin disrupts its cytoplasmic network of intermediate filaments and coincides temporally with nuclear fragmentation. Choi et al reported that vimentin is oxidized rapidly after glutamate treatment in HT22 cells (21).

Actin is the principal component of the eukaryotic cytoskeleton. Regulation of actin dynamics by actin-binding proteins is essential for control of cell shape, cytokinesis and motility. Among the actin-binding proteins, gelsolin and cofilin are already thought to be involved in the apoptosis process $(22,23)$. We observed alteration in cofilin 1 and transgelin 2 , suggesting that cytoskeletal remodeling may be involved in glutamate-induced toxicity of HT22.
Proteins involved in translation elongation. We observed alterations in several translational elongation factors including eukaryotic translation elongation factors (eEF)-1ß homolog, eEF-1 $\delta$ and eEF2 in both the cytosol and nucleus fractions consistent with previous reports regarding the regulatory role of translation factors in apoptosis (24). The role of eukaryotic translation initiation factor $2 \alpha$ in the protection of cells from oxidative stress was also suggested $(25,26)$. Additionally, mitochondrial translational elongation factor $\mathrm{Tu}$ was also detected as an up-regulated protein (27).

Post-translational modification and subcellular translocation. In many cases, we detected post-translational modification (PTM)-induced isoforms on our 2D DIGE gels. The most 
representative proteins with potential PTMs are eEF2 and HSP70 (Fig. 3A). eEF2 is a member of the GTP-binding translation elongation factor family and an essential factor for protein synthesis. This protein is known to be completely inactivated upon phosphorylation by eEF2 kinase, whose activity is dependent on $\mathrm{Ca}^{2+}$ and calmodulin. Glutamateinduced $\mathrm{Ca}^{2+}$ increase in HT22 cells may trigger phosphorylation of eEF2, halting the translation process. HSP70 was also detected at several spots. This protein is also known to be phosphorylated, but the role of the phosphorylation is unknown. In addition, several other potential PTMs were found in the 2D DIGE gels, but further analysis for verification and validation of their significance in HT22 cell death is required.

Transgelin 2, also known as SM22- $\alpha$ homolog (28), was detected as up-regulated in the cytosol but decreased in the nucleus. Interestingly, the pI values of this protein in the cytosol and nucleus are different, indicating that PTMs had also happened during translocation. Adenylate kinase 2 was known as a mitochondrial protein (29). However, we detected adenylate kinase 2 as an up-regulated protein in cytosol (Table I). Thus, adenylate kinase 2 may have translocated from the mitochondria to the cytosol. Adenylate kinase 2 translocation during apoptosis was previously reported by other groups $(30,31)$. It has been proposed that glutamate dehydrogenase 1 and isocitrate dehydrogenase 2 are localized in the mitochondrial matrix $(32,33)$. In our experiment, these enzymes were identified as up-regulated in the cytosol. Thus, these enzymes also have the potential for translocation from the mitochondria to the cytosol during HT22 cell death.

Oxidative stress is believed to occur during the pathogenesis of many neurodegenerative diseases. To understand the mechanism of oxidative stress induced neuronal cell death, we carried out extensive proteomic studies on the mouse hippocampal HT22 cell line. Traditional twodimensional polyacrylamide gel electrophoresis (2D-PAGE) of cell lysates is the basis of proteomic studies, but there are several technical limitations (34). To overcome these technical limitations, we adopted the 2D DIGE technique, which is aimed at improving reproducibility and decreasing inter-gel variation (35). In addition, the subcellular fractionation method was applied to reduce sample complexity and investigate the translocation of proteins between subcellular compartments. The use of two separate 24-cm IPG strips ( $\mathrm{pH} \mathrm{4-7} \mathrm{and} \mathrm{6-9)} \mathrm{further} \mathrm{reduced} \mathrm{the} \mathrm{sample}$ complexity. These allowed more low-abundant proteins to be visualized, from which a total of $>5,000$ protein spots were analyzed.

It has been reported that oxidative stress kills nerve cells via a pathway that is distinct from classical apoptosis (7). In contrast to classical apoptosis, there is no nuclear fragmentation, chromatin condensation, DNA fragmentation, or caspase 3 processing/activation in glutamate-induced nerve cell death. In our studies, exposure of mouse neuronal HT22 cells to oxidative glutamate toxicity induced major changes in the global protein expression pattern. We also did not detect changes in the proteins involved in nuclear fragmentation, chromatin condensation, or DNA fragmentation. Apoptosisinducing factor (AIF), a mitochondrial flavoprotein, translocates to the nucleus upon apoptosis induction, where it triggers caspase-independent nuclear changes. In our study,
HSP70 was up-regulated in the glutamate-treated cytosol fraction. HSP70 is known to inhibit apoptosis by neutralizing and interacting with AIF (36). Overexpression of HSP70 also ameliorates glutamate-induced cell death in HT22 cells (18). More extensive studies are needed to elucidate whether HSP70 interacts with AIF or if AIF has certain functional roles in glutamate-induced cell death.

The proteome analysis in this study revealed changes in translational elongation machinery during HT22 cell death. In the case of translation initiation, eIF $2 \alpha$ and eIF5A were already known to be involved in the apoptosis pathway $(24,25,37)$. However, little is known regarding the role of translation elongation factors in apoptosis. In our analyses, we detected significant changes in several translation elongation factors, including eEF2 and mitochondrial translation elongation factor Tu. eEF2 was identified at several spots located horizontally on 2D DIGE gels, implying multiple protein PTMs. Consistent with this finding, eEF2 is known to be phosphorylated after cellular stress and phosphorylation deactivates eEF2 (38). The intensity of the 2D gel spot corresponding to the mitochondrial translational elongation factor Tu was increased, indicating that HT22 cell death involves mitochondrial protein synthesis. These results imply that translational elongation control as well as translational initiation control are important functional factors in the oxidative stress response of HT22 cells.

In addition to the differential expression of proteins, translocation between subcellular organelles was observed in proteins such as transgelin 2 and adenylate kinase 2. During apoptosis, the movement of proteins, including cytochrome c, AIF, and EndoG, in or out of mitochondria is essential (39). The cytoskeletal protein cofilin was found to translocate from the cytosol to the mitochondria after induction of apoptosis, playing an important function during the initiation phase of apoptosis (39). Interestingly, in our analyses, cofilin was increased in the cytosol after glutamate treatment. The difference may originate from different cell types and/or phases of apoptosis, but this requires further validation. Glutamate dehydrogenase 1 appears to translocate from the mitochondrial matrix to the cytosol. In the normal brain, glutamate dehydrogenase 1 is involved in learning and memory by increasing turnover of the excitatory neurotransmitter glutamate (40). Increased levels of glutamate dehydrogenase 1 likely play a role in metabolizing excess intracellular glutamate in HT22 cell death.

In summary, the extensive proteomic studies utilizing the 2D DIGE technique identified various proteins playing important roles in glutamate-induced HT22 cell death. The varied expression levels, PTMs, and subcellular translocations of the proteins clarify the mechanisms underlying oxidative stress-induced neuronal cell death that often occurs during ischemic brain damage.

\section{Acknowledgments}

We thank Dr David Schubert for HT22 cells, Dr Seung-Jun Kim and Dr Eui-Jeon Woo for helpful advice and Dr Sunghyun Kang for critical reading of the manuscript. This research was supported by grants from KRIBB Research Initiative Program (to S.E. Ryu) and KRIBB Open Innovation Program (to K.-H. Bae). 


\section{References}

1. Beal MF: Aging, energy, and oxidative stress in neurodegenerative diseases. Ann Neurol 38: 357-366, 1995.

2. Simonian NA and Coyle JT: Oxidative stress in neurodegenerative diseases. Annu Rev Pharmacol Toxicol 36: 83-106, 1996.

3. Pettmann B and Henderson CE: Neuronal cell death. Neuron 20: 633-647, 1989 .

4. Dawson VL and Dawson TM: Deadly conversations: nuclearmitochondrial cross-talk. J Bioeneg Biomemb 36: 287-294, 2004.

5. Bertram $\mathrm{C}$ and Hass R: Cellular responses to reactive oxygen species-induced DNA damage and aging. Biol Chem 389: 211-220, 2008 .

6. Tan S, Wood M and Maher P: Oxidative stress induces a form of programmed cell death with characteristics of both apoptosis and necrosis in neuronal cells. J Neurochem 71: 95-105, 1998.

7. Tan S, Schubert D and Maher P: Oxytosis: A novel form of programmed cell death. Curr Top Med Chem 1: 497-506, 2001.

8. Kang TH, Bae K-H, Yu MJ, Hwang HR, Jung H, Lee PY, Kang S, Yoon T-S, Park SG, Ryu SE and Lee SC: Phosphoproteomic analysis of neuronal cell death by glutamate-induced oxidative stress. Proteomics 7: 2624-2635, 2007.

9. Maher P and Davis JB: The role of monoamine metabolism in oxidative toxicity. J Neurosci 16: 6394-6401, 1996.

10. Rossler OG, Giehl KM and Thiel G: Neuroprotection of immortalized hippocampal neurones by brain-derived neurotrophic factor and Raf-1 protein kinase: role of extracellular signal-regulated protein kinase and phosphatidylinositol 3-kinase. J Neurochem 88: 1240-1252, 2004.

11. Huber LA, Pfaller K and Vietor I: Organelle proteomics: implications for subcellular fractionation in proteomics. Circ Res 92: 962-968, 2003.

12. Kim SY, Lee PY, Shin H-J, Kim DH, Kang S, Moon HB, Kang SW, Park BC, Park SG, Yu DY, Bae K-H and Lee SC: Proteomic analysis of liver tissue from $\mathrm{HBx}$-transgenic mice at early stages of hepatocarcinogenesis. Proteomics 9: 5056-5066, 2009.

13. Leppa S, Kajanne R, Arminen L and Sistonen L: Differential induction of Hsp-70-encoding genes in human hematopoietic cells. J Biol Chem 276: 31713-31719, 2001.

14. Groenendyk J, Lynch J and Michalak M: Calreticulin, $\mathrm{Ca}^{2+}$, and calcineurin-signaling from the endoplasmic reticulum. Mol Cells 17: 383-389, 2004

15. Rossler OG, Bauer I, Chung H-Y and Thiel G: Glutamateinduced cell death of immotalized murine hippocampal neurons: neuroprotective activity of heme oxygenase-1, heat shock protein 70, and sodium selenite. Neurosci Lett 362: 253-257, 2004.

16. Beckmann RP, Mizzen LE and Welch WJ: Interaction of Hsp 70 with newly synthesized proteins: implications for protein folding and assembly. Science 248: 850-854, 1990.

17. Shi Y and Thomas JO: The transport of proteins into the nucleus requires the 70 -kilodalton heat shock protein or its cytosolic cognate. Mol Cell Biol 12: 2186-2192, 1992.

18. Zitzler J, Link D, Schafer R, Liebetrau W, Kazinski M, Bonin-Debs A, Behl C, Buckel P and Brinkmann U: Highthroughput functional genomics identifies genes that ameliorate toxicity due to oxidative stress in neuronal HT-22 cells: GFPT2 protects cells against peroxide. Mol Cell Proteomics 3: 834-840, 2004

19. Lee SM, Koh HJ, Park DC, Song BJ, Huh TL and Park JW: Cytosolic NADP(+)-dependent isocitrate dehydrogenase status modulates oxidative damage to cells. Free Radic Biol Med 32: 1185-1196, 2002.

20. Byun Y, Chen F, Chang R, Trivedi M, Green KJ and Cryns VL: Caspase cleavage of vimentin disrupts intermediate filaments and promotes apoptosis. Cell Death Differ 8: 443-450, 2001.

21. Choi J, Conrad CC, Dai R, Malakowsky CA, Talent JM Carroll CA, Weintraub ST and Gracy RW: Vitamin E prevents oxidation of antiapoptotic proteins in neuronal cells. Proteomics 3: $73-77,2003$
22. Burtnick LD, Urosev D, Irobi E, Narayan K and Robinson RC: Structure of the N-terminal half of gelsolin bound to actin: roles in severing, apoptosis and FAF. EMBO J 21: 2713-2722, 2004.

23. Klamt F, Zdanov S, Levine RL, Pariser A, Zhang Y, Zhang B, Yu LR, Veenstra TD and Shacter E: Oxidant-induced apoptosis is mediated by oxidation of the actin-regulatory protein cofilin. Nat Cell Biol 11: 1241-1246, 2009.

24. Thornton S, Anand N, Purcell D and Lee J: Not just for housekeeping: protein initiation and elongation factors in cell growth and tumorigenesis. J Mol Med 81: 536-548, 2003.

25. Boyce M, Bryant KF, Jousse C, Long K, Harding HP, Scheuner D, Kaufman RJ, Ma D, Coen DM, Ron D and Yuan J: A selective inhibitor of eIF2A dephosphorylation protects cells from ER stress. Science 307: 935-939, 2005.

26. Holcik M and Sonenberg N: Translational control in stress and apoptosis. Nat Rev Mol Cell Biol 6: 318-327, 2005.

27. Shadel GS: Coupling the mitochondrial transcription machinery to human disease. Trends Genet 20: 513-519, 2004.

28. Chen S, Kulik M and Lechleider RJ: Smad proteins regulate transcriptional induction of the SM22 $\alpha$ gene by TGF- $\beta$. Nuc Acids Res 31: 1302-1310, 2003

29. Kohler C, Gahm A, Noma T, Nakazawa A, Orrenius S and Zhivotovsky B: Release of adenylate kinase 2 from the mitochondrial intermembrane space during apoptosis. FEBS Lett 447: 10-12, 1999.

30. Moosmann B and Behl C: Antioxidants as treatment for neurodegenerative disorders. Expert Opin Investig Drugs 11: 1407-1435, 2002.

31. Van Loo G, Demol H, van Gurp M, Hoorelbeke B, Schotte P, Beyaert R, Zhivotovsky B, Gevaert K, Declercq W, Vandekerckhove $\mathrm{J}$ and Vandenabeele P: A matrix-assisted laser desorption ionization post-source decay (MALDI-PSD) analysis of proteins released from isolated liver mitochondria treated with recombinant truncated Bid. Cell Death Diff 9: 301308, 2002.

32. Vorhaben JE and Campbell JW: Submitochondrial localization and function of enzymes of glutamine metabolism in avian liver. J Cell Biol 73: 300-310, 1977.

33. Mihara K, Omura T, Harano T, Brenner S, Fleischer S, Rajagopalan KV and Blobel G: Rat liver L-glutamate dehydrogenase, malate dehydrogenase, D-ß-hydroxybutyrate dehydrogenase, and sulfite oxidase are each synthesized as larger precursors by cytoplasmic free polysomes. J Biol Chem 257: 3355-3358, 1982 .

34. Gorg A, Weiss W and Dunn MJ: Current two-dimensional electrophoresis technology for proteomics. Proteomics 4: 3665-3685, 2004.

35. Minden JS, Dowd SR, Meyer HE and Stuhler K: Difference gel electrophoresis. Electrophoresis (Suppl 1): S156-S161, 2009.

36. Gurbuxani S, Schmitt E, Cande C, Parcellier A, Hammann A, Daugas E, Kouranti I, Spahr C, Pance A, Kroemer G and Garrido C: Heat shock protein 70 binding inhibits the nuclear import of apoptosis-inducing factor. Oncogene 22: 6669-6678, 2003.

37. Li AL, Li HY, Jin BF, Ye QN, Zhou T, Yu XD, Pan X, Man JH, He K, Yu M, Hu MR, Wang J, Yang SC, Shen BF and Zhang XM: A novel eIF5A complex functions as a regulator of p53 and p53-dependent apoptosis. J Biol Chem 279: 49251-49258, 2004.

38. Patel J, McLeod LE, Vries RG, Flynn A, Wang X and Proud CG: Cellular stresses profoundly inhibit protein synthesis and modulate the states of phosphorylation of multiple translation factors. Eur J Biochem 269: 3076-3085, 2002.

39. Chua BT, Volbracht C, Tan KO, Li R, Yu VC and Li P: Mitochondrial translocation of cofilin is an early step in apoptosis induction. Nat Cell Biol 5: 1083-1089, 2003.

40. Sakimura K, Kutsuwada T, Ito I, Manabe T, Takayama C, Kushiya E, Yagi T, Aizawa S, Inoue Y, Sugiyama $\mathrm{H}$ and Mishina M: Reduced hippocampal LTP and spatial learning in mice lacking NMDA receptor $\gamma 1$ subunit. Nature 373: 151-155, 1995. 